\title{
Inovação na cooperação intermunicipal no Brasil: a experiência da Federação Catarinense de Municípios (Fecam) na construção de consórcios públicos
}

\author{
Fernando Luiz Abrucio \\ EAESP/Fundação Getulio Vargas - FGV \\ Eliane Salete Filippim \\ Universidade do Oeste de Santa Catarina - Unoesc \\ Rodrigo Chaloub Dieguez \\ Valec Engenharia, Construções e Ferrovias S.A.
}

\begin{abstract}
Este artigo analisa uma experiência inovadora de cooperação intermunicipal no Brasil, por meio da observação da atuação da Federação Catarinense de Municípios (Fecam) no fomento e na organização de consórcios públicos intermunicipais. Investiga o uso de uma estratégia singular para enfrentar determinados limites à montagem de formas de consórcio no Brasil, entre os quais a dificuldade dos municípios, sem algum estímulo externo, para construir parcerias estáveis entre si. O ponto central da análise realça a possibilidade de associações municipalistas induzirem a cooperação de forma mais duradoura e com maior sustentação técnica. Com base no estudo de caso qualitativo, observou-se a atuação da Fecam como advocacy e como estrutura institucional profissionalizada que fomenta a cooperação entre municípios.
\end{abstract}

Palavras-chave: cooperação intermunicipal; associação municipalista; consórcio público.

Innovación en la cooperación intermunicipal en Brasil: la experiencia de la Federação Catarinense de Municípios (Fecam) en la construcción de consorcios públicos

Este artículo analiza una experiencia innovadora de cooperación intermunicipal en Brasil, por medio de la observación de la actuación de la Federação Catarinense de Municípios (Fecam) en el fomento y en la organización de consorcios públicos intermunicipales. Investiga el uso de una estrategia singular para afrontar determinados límites al montaje de formas de consorcio en Brasil, entre los cuales la dificultad de los municipios, sin algún estímulo externo, para construir sociedades estables entre sí. El punto central del análisis realza la posibilidad de asociaciones municipalistas indujeren la cooperación de forma más duradera y con mayor sustentación técnica. Con base en el estudio de caso cualitativo,

Artigo recebido em 8 jun. 2012 e aceito em 17 jul. 2013.

Rev. Adm. Pública - Rio de Janeiro 47(6):1543-568, nov./dez. 2013 
se observó la actuación de la Fecam como advocacy y como estructura institucional profesionalizada que fomenta la cooperación entre municipios.

Palabras clave: cooperación intermunicipal; asociación municipalista; consorcio público.

Innovation in inter-municipal cooperation in Brazil: the experience of Federação Catarinense de Municípios (Fecam) in the construction of public consortia

This article analyzes an innovative experience of inter-municipal cooperation in Brazil, by observing the work of Federação Catarinense de Municípios (Fecam) for promoting and organizing inter-municipal public consortia. It investigates the use of a singular strategy to face certain limits to the creation of consortium forms in Brazil, among them the difficulty of towns, without some external stimulus, to construct stable partnerships between themselves. The key point of the analysis highlights the possibility that municipalist associations induce a more durable cooperation with an increased technical support. Based on the qualitative case study, we observed the work of Fecam as advocacy and as a professionalized institutional structure which promotes cooperation between towns.

KEYWORDs: inter-municipal cooperation; municipalist association; public consortium.

\section{Introdução}

O tema da cooperação federativa tornou-se fundamental na agenda política e de pesquisa no Brasil. Isso tem ocorrido, principalmente, porque a dicotomia centralização versus descentralização mostra-se cada vez mais desgastada como chave para entender a dinâmica do federalismo brasileiro. Em vez dessa lógica binária, parte importante dos estudos internacionais e nacionais realça a necessidade de construir mecanismos de coordenação e parceria entre os níveis de governo para resolver dilemas de ação coletiva e problemas das políticas públicas (ver, entre outros, Elazar, 1987; Agranoff, 2001; Abrucio, 2005; Franzese, 2010; Lício, 2010). Em consonância com essa visão, duas soluções intergovernamentais têm ganhado força no Brasil: os sistemas de políticas públicas, como o Sistema Único de Saúde (SUS) e seus correlatos noutros setores, e as formas de associativismo territorial, em particular, o instrumento dos consórcios entre governos locais.

$\mathrm{O}$ artigo trata da segunda solução intergovernamental, o associativismo territorial, mais especificamente a construção de Consórcios Públicos. A importância desse tópico federativo deriva da constatação de que os municípios não podem, em muitos casos, resolver sozinhos seus problemas de políticas públicas e obtêm melhor sucesso para resolver questões quando se associam (Daniel, 2001; Spink, Teixeira e Clemente, 2009). Assim ocorre em áreas como saúde, resíduos sólidos, além de consorciamentos multissetoriais para o desenvolvimento (Abrucio e Soares, 2001).

Se aparentemente a melhor saída para os municípios é se associar, isso não quer dizer que necessariamente o farão e, se o fizerem, ademais, isso não garante que sua articulação intermunicipal será forte e/ou duradora. Na verdade, muitos estudos realçam as dificuldades 
para formar e manter fortes ou mesmo unidos os consórcios e outras formas de cooperação formal entre governos locais (Dieguez, 2011; Abrucio e Sano, 2013).

Diante desta realidade problemática, surgiram estudos analisando casos bem-sucedidos de consorciamento pelo país afora. Várias cooperativas advindas de lideranças municipalistas, de capital social regional, de indução pelos governos estaduais e derivados da nova Lei dos Consórcios Públicos, para ficar nas explicações mais citadas pela literatura, foram estudadas no processo de formação de consórcios. Pesquisam-se pouco, no entanto, as condições que geram a continuidade destas articulações intermunicipais.

Este trabalho procura trazer mais elementos para a compreensão da cooperação intermunicipal no Brasil, a partir do estudo empírico da atuação da Federação Catarinense de Municípios (Fecam) na organização de consórcios públicos intermunicipais em Santa Catarina (Sul do Brasil). ${ }^{1}$ É um caso singular na experiência federativa brasileira, uma vez que os consorciamentos são produzidos por uma associação municipalista, a qual tem um papel importante não somente na formação como também na manutenção de tais arranjos intermunicipais. Desse modo, é possível observar e compreender como um arranjo associativo de governos locais, que vai além das unidades municipais de cada consórcio, consegue criar e multiplicar parcerias estáveis entre municipalidades.

Embora limite a generalização das conclusões, a opção feita pelo estudo de caso permite compreender as características de uma experiência relevante e singular e, a partir de seu entendimento, podem surgir novas formas de ver um fenômeno maior (Yin, 2005). No caso em questão, a análise revela que o modelo adotado pela Fecam permite enxergar a formação e a manutenção dos arranjos intermunicipais de maneira diferente da que usualmente aparece no país e nos principais trabalhos sobre o assunto. Isto porque a Fecam é, ao mesmo tempo, uma entidade que aparece como externa aos municípios — podendo, inclusive, mediar os conflitos entre eles —, mas também é resultado da junção entre eles, de modo que eles são parte integrante dessa instituição. Esta dupla característica é que dá força à Fecam.

Em poucas palavras, o artigo pretende trazer novos elementos para a discussão analítica mais geral, mas também ressaltar o caminho específico da experiência catarinense em cooperação intergovernamental, determinando o quanto o modelo pode ser reproduzido ou não para outras realidades.

Há ainda poucos trabalhos sobre a dinâmica de implementação de Consórcios Públicos de Direito Público, que somente começaram a existir a partir da nova legislação de 2005. Assim, o estudo sobre as estratégias da Fecam para construir consórcios públicos acrescenta novo conhecimento ao campo da cooperação intergovernamental num ponto pouco conhecido à medida que observa a inserção dos municípios catarinenses na associação do tipo advocacy, conjugada a um trabalho de assessoria técnica.

\footnotetext{
${ }^{1}$ Este trabalho é resultado de pesquisa financiada pela Agência Espanhola de Cooperação Internacional para o Desenvolvimento (Aecid), quando foram estudadas 11 experiências de associativismo territorial no Brasil (Abrucio e Sano, 2013).
} 
O texto foi organizado da seguinte forma: na primeira seção, após breve introdução, são expostas as principais questões colocadas pelos estudos sobre cooperação intergovernamental. No tópico seguinte, o desenho da pesquisa é apresentado. Na próxima seção, é descrita a forma de atuação da Fecam para fomentar e manter Consórcios Públicos. Na sequência, procura-se entender a lógica deste tipo de cooperação intermunicipal, realçando em especial os pontos que favorecem a formação e a institucionalidade destes arranjos, bem como suas dificuldades, tendo como foco empírico especial o estudo sobre o Consórcio de Informática na Gestão Pública Municipal (Ciga). ${ }^{2}$ Conclui-se apresentando de que maneira o presente estudo de caso pode contribuir para o debate da cooperação intermunicipal.

\section{Referencial teórico: cooperação intergovernamental e consorciamento de municípios}

A constatação de que os municípios sozinhos não conseguem formular e implementar todas as políticas públicas os tem conduzido a buscar soluções cooperativas, especialmente por meio de consórcios e "a tendência consorciada tem, de fato, se fortalecido nos últimos anos, ganhando novos formatos institucionais, mas os empecilhos à cooperação continuam fortes" (Abrucio, Sano e Sydow, 2011:5).

Diante dos problemas locais e de cooperação entre os governos, o caso de Santa Catarina é muito singular na federação brasileira. Os municípios catarinenses têm constituído associações e federações, como é o caso da Fecam, como uma estrutura não só de advocacy - entendida como uma ação coletiva para identificar, adotar e promover uma causa e/ou determinados interesses dos associados (Breláz, 2007) —, mas também como mecanismo para ajudar a gestão municipal de seus associados, preferencialmente de forma consorciada. Não há em nenhum outro estado uma estrutura associativa municipal que atue desse modo.

Numa revisão da trajetória dos consórcios públicos no Brasil, Dieguez (2011) retoma que o consorciamento intermunicipal está previsto no Brasil desde a Constituição de 1937. Já Coutinho (2010) aponta que até a redemocratização eram poucos os consórcios públicos municipais e eles eram fortemente subordinados à política estadual. O fenômeno do consorciamento público se fortaleceu a partir da década de 1990 pela formação de redes federativas na busca de "melhor adequação entre as propriedades virtuosas da competição e da cooperação e da centralização e da descentralização" (Dieguez, 2011:282). Desde a Constituição de 1988, eles têm se multiplicado pelo país e ganharam, mais recentemente, um novo marco legal, com a Lei no 11.107/2005 dos Consórcios Públicos.

\footnotetext{
${ }^{2}$ Entende-se aqui que os consórcios intermunicipais são aqueles formados por uma rede federativa em que se constituiu uma arena política de cooperação horizontal entre dois ou mais entes federativos municipais, voltada para a produção compartilhada de decisões sobre políticas públicas. Já a associação não envolve necessariamente a produção de decisões compartilhadas, podendo servir apenas para representação de interesses comuns. A federação é a reunião de associações.
} 
Este tipo de consorciamento pode também ser entendido como a articulação de capital social, que, para Bourdieu (1980), é o conjunto de relações e redes de ajuda mútua que podem ser mobilizadas efetivamente para beneficiar indivíduos ou grupos sociais, com vistas a manter ou reforçar seu estatuto e seu poder na sociedade. O encrustamento (embeddedness) é viabilizado a partir de vínculos e redes entre duas ou mais esferas que diminuem sua distinção, gerando a base de normas e interações que contribuem para a realização de potenciais ganhos conjuntos. Tal relação pode ser alcançada por meio da aplicação criativa de novas formas de construção institucional e mudança organizacional, dependendo, dessa forma, mais da maneira como as políticas públicas são formuladas e da existência de interesses compartilhados entre os atores envolvidos e suas capacidades de identificar tal confluência, do que de características histórico-culturais (Castellano, 2007:40-42).

Os consórcios intermunicipais de saúde constituem a experiência setorial mais bemsucedida e com maior número de estudos. Neves e Ribeiro (2006) destacam que tais consorciamentos têm favorecido estratégias inovadoras que geram a produção de soluções regionais pactuadas. Salientam que as coalizões feitas em torno destes consórcios têm aumentado a cooperação entre os participantes, mesmo de diferentes partidos políticos.

Em outros temas intersetoriais também tem crescido a mobilização pelo consorciamento. Entre os fatores que são citados na literatura como favorecedores do consorciamento intermunicipal, podem ser destacados os seguintes (Abrucio e Sano, 2013):

a) A existência de uma identidade regional prévia que abarque um conjunto de municípios, tornando-se um catalisador político e social que favorece a atuação conjugada. Normalmente esse fenômeno é construído ao longo do tempo e/ou por um fato muito marcante que crie laços comuns, e tal identidade regional pode ser mais realçada caso haja forte capital social inscrito nas instituições locais.

b) A constituição de lideranças políticas regionais que são capazes, mesmo em contextos adversos, de produzir alianças intermunicipais.

c) Questões que envolvem "tragédias dos comuns", isto é, problemas coletivos que atingem vários municípios de tal modo que a cooperação se torna necessária para que ninguém seja prejudicado.

d) A lógica das políticas públicas pode impulsionar formas de consorciamento, especialmente quando suas regras sistêmicas e/ou seus mecanismos de indução financeira apontam nesse sentido, como tem acontecido na área de Resíduos Sólidos, na qual a legislação definiu que o governo federal só repassa recursos a municípios que atuarem sob regime de Consórcio Público.

e) O apoio e indução do governo estadual e/ou federal é outro instrumento que pode incentivar a criação e manutenção de consórcios, reduzindo rivalidades e incertezas que possam existir entre os prefeitos. 
f) Pactos políticos, ad hoc, entre prefeitos e governadores podem favorecer o associativismo intermunicipal quando estão em jogo questões que favoreçam, pelo menos conjunturalmente, a ambos.

g) A existência de marcos legais que tornem mais atrativa e estável a cooperação intermunicipal pode incentivar os atores a buscar formas de consorciamento. A promulgação da Lei dos Consórcios Públicos teve, em certa medida, este efeito.

Há vários aspectos que podem dificultar a construção de formas de cooperação no Brasil. Ao comparar o quadro geral de consórcios no Brasil e analisar detidamente 11 experiências, Abrucio e Sano (2011:66-68) apontaram as seguintes variáveis como desfavorecedoras da cooperação intermunicipal: comportamento individualista e autárquico dos municípios; ausência de uma identidade regional, acoplada ao baixo capital social das instituições locais; brigas político-partidárias, entre prefeitos ou destes com o governador; engessamento do direito administrativo e de sua interpretação por parte dos Tribunais de Contas, que criam obstáculos ao associativismo intermunicipal; falta de indução federativa advinda dos outros níveis de governo, especialmente dos governos estaduais; gestão pública frágil, o que dificulta a obtenção de informação e conhecimento sobre a montagem de consórcios; conflitos intergovernamentais em determinadas políticas públicas, como no caso da educação e seu ineficiente "regime de colaboração"; e o lugar pouco destacado que a questão territorial e, particularmente, a do associativismo, ainda têm na agenda pública brasileira.

No balanço entre fatores positivos e adversos, de um lado, constata-se que as formas de consorciamento têm provavelmente crescido menos do que as necessidades de cooperação intermunicipal, mas, de outro lado, há um aumento e uma diversificação crescentes nos tipos de associativismo territorial no Brasil. Os avanços apontados pela literatura, no entanto, concentram-se fortemente na capacidade de formar consórcios, e a maioria dos estudos empíricos não analisa se houve continuidade destes arranjos intermunicipais.

Como aponta Dieguez (2011:293), a questão dos consórcios envolve entender não somente o que leva à sua criação, mas também devem ser explicadas as variáveis que garantem a estabilidade institucional dos consorciamentos. O caso da Fecam é interessante para o debate da cooperação intermunicipal no Brasil por tocar nas questões que são centrais para a reflexão teórica: como montar o consorciamento e de que maneira mantê-lo estável — e funcionando bem - ao longo do tempo?

Em síntese, pode-se dizer que o desafio teórico está em responder a uma questão central, levantada por Ostrom (1990) e sistematizada por Dietz, Ostrom e Stern (2003): como um grupo que partilha uma situação de interdependência pode organizar a si próprio, construindo uma estrutura institucional que mantenha a produção compartilhada de benefícios contínuos e sustentáveis, sem que seus integrantes se sintam atraídos pelas externalidades negativas de processos de cooperação?

A experiência aqui estudada traz respostas instigantes a estas perguntas. Primeiro, porque revela uma forma diferente de se construir consórcios, enfrentando, dessa maneira, uma série dos obstáculos apontados anteriormente como limite para construção e expansão do 
associativismo territorial local. Segundo, a maneira como são organizados os consorciamentos por esta associação municipalista favorece a estabilidade e a disseminação de tais arranjos, apresentando elementos essenciais ao debate da institucionalização da cooperação federativa. Ao trazer um novo modelo, a experiência da Fecam não gera um padrão que deva ser simplesmente replicado por todo o país, até porque a federação brasileira é bastante heterogênea e não é possível encontrar um paradigma único para ela - ao contrário, cabe mais uma proposta de cardápio do que de homogeneização forçada. Contudo, observando do ponto de vista analítico, a criação de um ator neutro em face das barganhas e dos conflitos intergovernamentais envolvidos na montagem dos consórcios, além da estruturação de uma instituição permanente com um corpo profissionalizado capaz de reduzir as fragilidades técnicas e as incertezas de mudança de governo nos municípios, são dois pontos que podem ser colocados como preocupação generalizante a toda e qualquer cooperação intermunicipal.

\section{Procedimentos metodológicos}

Nesta seção apresenta-se o desenho utilizado na pesquisa que fundamentou este artigo. Adotou-se como estratégia de investigação o estudo de caso único, com a descrição mais próxima de um consórcio protagonizado pela Fecam. Faz-se necessário esclarecer que neste estudo são abordados múltiplos espaços: o município, as associações regionais de municípios, a organização destes municípios em uma federação, a Fecam; esta atua como advocacy em favor dos interesses comuns dos municípios.

De acordo com Yin (2005), o caso único tem um enfoque holístico e permite entender melhor situações raras ou novas, como é o caso da Fecam, cuja principal marca é sua originalidade de produzir consorciamento público a partir de uma associação municipalista de advocacy. Cabe ressaltar que o estudo de caso deve se cercar de várias fontes de pesquisa e dialogar com as explicações mais gerais, realçando a singularidade do objeto observado e como ele pode ser compreendido.

Após percorrer a literatura sobre o associativismo territorial local no Brasil, não se encontrou nenhum estudo sobre a ação de entidades municipalistas em prol de arranjos de cooperação intermunicipal. Aliás, o tema em si das associações municipalistas é negligenciado pelos pesquisadores brasileiros, a despeito de haver 262 associações municipalistas no país, de âmbito microrregional, estadual, macrorregional e nacional (Abrucio, Sano e Sydow, 2011). Esta lacuna na academia brasileira é enfrentada aqui, por meio do estudo da Fecam.

Para Godoy (2010:119), “(...) a especificidade do estudo de caso (...) está no tipo de questão que ele responde cujo foco de interesse está no individual, no específico”. Portanto, o objeto de análise é a cooperação intermunicipal, com foco numa ação da Fecam na construção de consórcios. Optou-se por descrever especificamente o protagonismo dessa federação na implantação do Consórcio de Informática na Gestão Pública Municipal (Ciga), pois essa experiência é exemplar para observar a forma como a Fecam tem atuado singularmente como advocacy e na implantação de consórcios. Compreende-se que o olhar focalizado sobre esse 
evento (a criação e condução do consórcio Ciga) permita fazer emergir reflexões acerca desse tipo de cooperação intermunicipal.

Como recomendado por Godoy (2010), para dar robustez a um estudo de caso, deve-se fazer uso de múltiplas fontes de dados. Nesse sentido, para a compreensão deste fenômeno particular estudado, a coleta de dados ocorreu nas seguintes fontes: estudo de casos correlatos, análise de documentos, realização de entrevistas semiestruturadas e observação direta da prática dos atores. Os documentos (atas, legislação, publicações) consultados foram aqueles disponibilizados pela Fecam e outros obtidos nos municípios consorciados ao Ciga.

Quatro entrevistas semiestruturadas e focalizadas foram realizadas com o diretor executivo da Fecam, com os diretores executivos do Ciga e da Agência Reguladora Intermunicipal de Saneamento (Aris). Também foi entrevistada uma técnica do Ciga, no ano de 2011, e novamente para atualização de dados em 2013. Foram ainda realizadas três entrevistas com representantes de três municípios membros do consórcio Ciga, com a finalidade de observar a recepção da atuação do consórcio entre os associados. Para melhor observar os aspectos singulares deste consorciamento fomentado pela Fecam, fizeram-se também duas entrevistas com membros de outros consórcios públicos catarinenses.

Para este estudo, a observação prática da atuação da Fecam na articulação de consórcios públicos se deu também pela participação dos pesquisadores em eventos da Fecam e, particularmente, pela participação em reunião específica de difusão do consórcio Ciga em uma das associações de municípios filiada à Fecam. Os dados observados foram analisados segundo os mesmos critérios utilizados para a análise das entrevistas e dos dados documentais. Os critérios eleitos para busca e análise dos dados e que orientaram a organização, descrição e análise, tanto do caso Fecam quanto do Ciga, versaram sobre os seguintes aspectos: o tipo do arranjo; os fatores que explicam a formação e criação do arranjo; os mecanismos de indução; as fontes de financiamento; a estrutura administrativa e o setor de atuação; principais relações do arranjo; grau de autonomia; o processo decisório e a inovação; transparência, publicização e comunicação; os instrumentos de avaliação; participação social no arranjo; os resultados; dificuldades encontradas no momento da criação do arranjo; e, por fim, os fatores que explicam a permanência e a sobrevivência do arranjo.

\section{Resultados e análise}

O artigo foi organizado intencionalmente sem uma separação rígida entre apresentação e análise de dados, adotando assim uma estratégia que visa favorecer a reflexão acerca da realidade empírica no momento em que ela é apresentada.

\subsection{As origens da Fecam: condições prévias e inovações}

O associativismo municipalista em Santa Catarina é um dos mais antigos e mais estruturados da federação brasileira. O estudo de sua experiência singular é uma forma de entender o que 
há nesse caso que poderia ser usado para compreender esse caráter seminal, bem como o que existe nessa experiência que poderia ser utilizado para pensar a disseminação de tal associativismo territorial para outros estados.

\subsubsection{O tipo do arranjo e os fatores explicam a sua formação}

A origem do processo cooperativo aconteceu no nível microrregional nos anos 1960; a primeira associação de municípios do estado foi criada no interior do estado, em Joaçaba, em 1961. Foram criadas por iniciativa dos prefeitos, especialmente aqueles do Oeste, que percebiam certo abandono do interior do estado por parte do governo central de Florianópolis. Uma vez que enfrentavam dificuldades comuns e que, na maioria das vezes, extrapolavam tanto a capacidade de investimento quanto os limites de atuação dos municípios, tais prefeituras resolveram unir forças e criar associações de municípios, num contorno geográfico próximo às já estabelecidas relações anteriores de vizinhança e cooperação. Atualmente existem 22 associações de municípios em Santa Catarina.

Figura 1

Associações de municípios pertencentes à Fecam

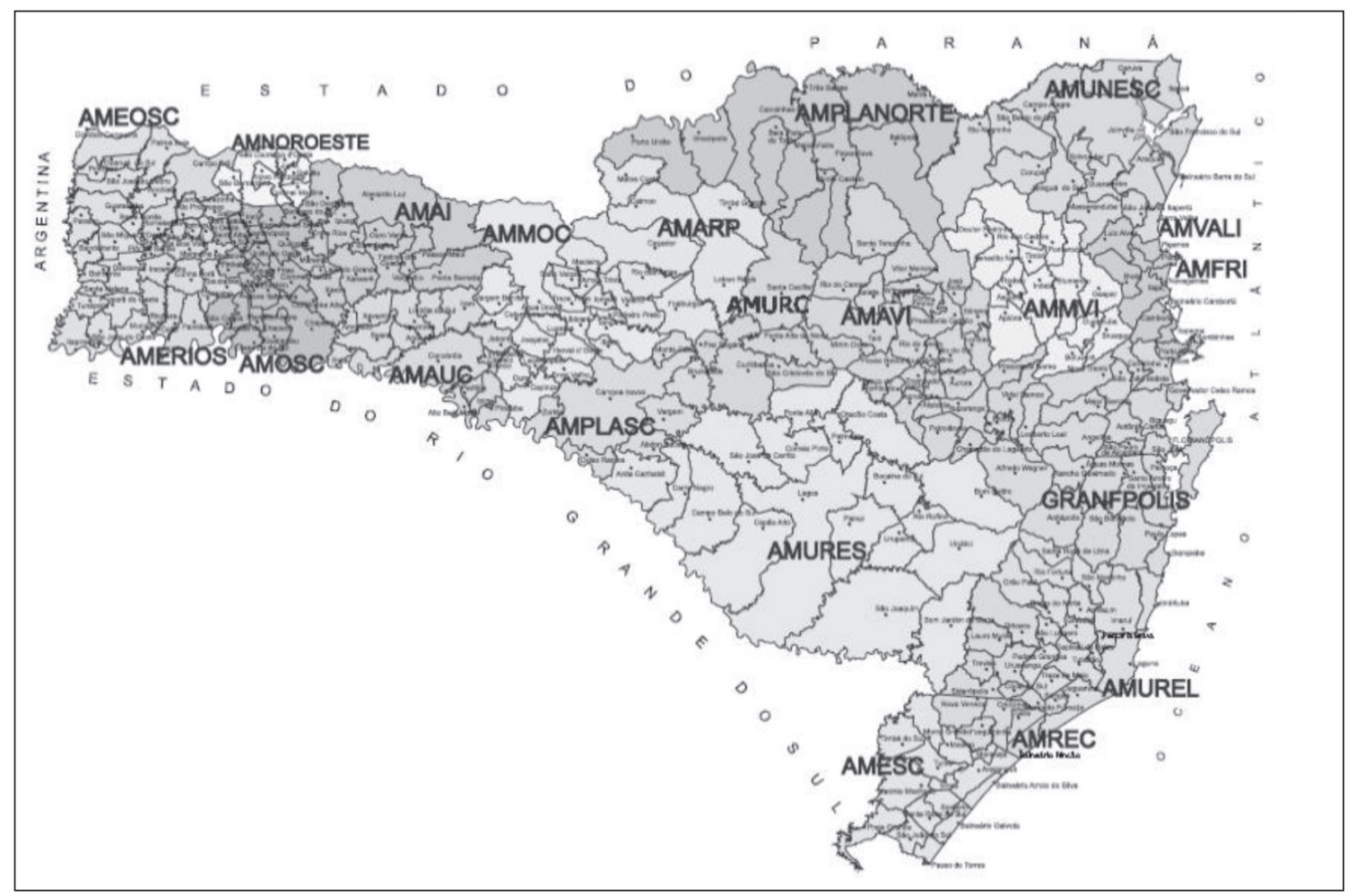

Fonte: Fecam (2013). 
O caso catarinense, de formação de consórcios por meio de associação de municípios, parece ser um modelo institucional interessante, não só porque ele tem sido bem-sucedido na conformação desses arranjos, mas também porque o faz por meio de uma estratégia que diminui a desconfiança entre as partes, estabelece diálogo e negociação contínuos com os municípios e implementa este processo mediante uma estrutura profissionalizada e com maior capacidade técnica do que a dos próprios governos locais.

A experiência desse associativismo regional e a necessidade de uma entidade que fizesse a interlocução destas associações com o governo estadual e federal fomentaram a criação da Fecam em julho de 1980. Esse arranjo associativo de base territorial é constituído de pessoa jurídica de direito privado, de natureza civil, sem fins econômicos, com tempo de duração indeterminado e sede administrativa em Florianópolis (SC).

Alguns fatores explicam a formação desse arranjo. Entre eles destacam-se a experiência das associações microrregionais existentes em SC anteriores à Fecam; a necessidade de interlocução e representação dos municípios ante o estado e a União, neste último caso vinculada principalmente ao contexto ainda de forte centralização vigente no regime militar.

Estes prefeitos, inspirados na articulação nacional ocorrida no final de 1970, trouxeram para Santa Catarina a proposta da criação de uma federação que articulasse as associações regionais de municípios atuantes no estado e que fizesse a defesa dos interesses dos municípios. Essa atuação reivindicatória foi complementada, nos anos 2000, pela forte ação em assessoria técnica realizada hoje pela Fecam (Vedana, 2011). Eis aí uma das características distintivas da Fecam em comparação com outras associações municipalistas: ela junta atividade de advocacy federativo com a de assessoria técnica. A mistura dessas duas funções lhe promove maior credibilidade para montar atividades que entrelacem os governos locais em torno de consorciamentos.

\subsubsection{Os mecanismos de indução para o arranjo associativo}

Para a criação da Fecam não houve mecanismo de indução direto da parte da União ou do governo estadual. Aponta-se apenas como mecanismo indireto de indução do governo federal aquele que ocorreu antes da criação da Fecam, quando a União apoiou, na década de 1960, a criação de associações de municípios por meio da ação da Superintendência de Desenvolvimento da Região Sul (Sudesul). O objetivo então era estabelecer uma relação mais direta com os municípios, principalmente de dependência e controle, típica do período militar, com seu "unionismo autoritário" (Abrucio, 1998).

Pode-se considerar, ainda, como mecanismo de indução indireta, que o Ministério do Planejamento e a Secretaria de Planejamento, do governo estadual, forneceram, na organização inicial da Fecam, orientação técnica sobre os processos e os serviços que ela prestaria aos municípios. A Secretaria do Planejamento de SC contribuiu inclusive com recursos financeiros após a instalação da Fecam, já num contexto em que a pressão por redemocratização gerava uma nova dinâmica federativa, na qual governadores e prefeitos atuavam conjuntamente. 
Esse auxílio foi importante para incrementar as capacidades institucionais da Fecam, mas não foi decisivo nem para sua formação, nem para a construção de uma estratégia de regionalização via consórcios intermunicipais. Isso porque, por vezes, tal modelo de atuação tem se chocado, em Santa Catarina, com os interesses políticos do governo estadual.

Analisando a gênese e construção da Fecam, constata-se um contexto singular presente em Santa Catarina, onde já há uma tradição maior de associativismo local em comparação ao resto do país, sendo o Rio Grande do Sul o único caso a rivalizar com essa situação. Mas também há um parâmetro comum: a Fecam surgiu no período da redemocratização, quando o municipalismo se organizou em quase todo o território nacional, basicamente como uma força de advocacy. A questão que salta à vista, no plano comparativo, foi a construção institucional da Fecam, que a levou a ter um trabalho de assessoria muito qualificada aos governos locais, algo que se somou a seu projeto de regionalização. Tais singularidades não se explicam somente pela tradição mais associativista de Santa Catarina, o que permite pensar a possibilidade de que tal experiência tem potencial importante de disseminação.

\subsection{Estrutura institucional e funcionamento da Fecam: qualidades e problemas}

Para entender melhor o fenômeno em questão, é fundamental descrever e analisar a estrutura institucional da Fecam, para caracterizar e compreender a singularidade dessa instituição.

\subsubsection{A estrutura administrativa, o setor de atuação e as fontes de financiamento}

A Fecam é regida por Estatuto e por Regimento interno, e suas fontes de financiamento provêm dos municípios catarinenses dela associados. Os recursos à disposição da Fecam vêm da contribuição dos municípios associados. O Orçamento de 2013 prevê receitas e despesas da ordem de $\mathrm{R} \$ 4.180 .000,00$. Atualmente tem como foco duas frentes de atuação: a representação institucional e política dos 293 municípios catarinenses, e a técnica, especializada em assessorias jurídica, contábil, tributária, social, entre outras, para atender às demandas dos municípios.

Quanto à estrutura administrativa, a Fecam é gerida por: Assembleia Geral, Conselho Deliberativo, Conselho Executivo e Conselho Fiscal. A execução dos trabalhos fica a cargo da Diretoria Executiva. Entendendo que seu foco de atuação é o município como ente jurídico, não existe, na estrutura da Fecam, nenhum colegiado que represente diretamente a população catarinense, nem de maneira consultiva e menos ainda deliberativa.

Segundo o Regimento Interno da Fecam, o critério da contratação ou disposição do pessoal técnico interno deverá obrigatoriamente obedecer a parâmetros de capacidade profissional e habilitação técnica para a função, evitando-se indicações político-partidárias. Essa profissionalização constitui um fator importante para explicar os objetivos e o modus operandi da Fecam. 
Observou-se, pelo estudo de documentos durante a pesquisa, que a Fecam visa atender aos interesses comuns dos 293 municípios catarinenses, compreendidos os órgãos públicos executivos e legislativos, de maneira intersetorial, nas áreas jurídica, contábil, social, tributária, meio ambiente, administrativa, tecnologias de informação, ferramentas para controles, turismo e cultura, entre outras, seguindo a demanda dos municípios e/ou se antecipando e oferecendo soluções às suas necessidades. Essas atividades são realizadas com um quadro enxuto de 27 empregados, todos contratados em regime CLT, por meio de processo seletivo específico.

\subsubsection{Grau de autonomia e principais relações do arranjo}

Do ponto de vista institucional, o arranjo associativo territorial descrito não depende de nenhum ente externo. Sua dependência é exclusiva dos associados: os municípios. Contudo, na atividade de representação dos pleitos dos municípios, a Fecam depende do entendimento e da vontade política das instituições com as quais interage, mas pode atuar mais autonomamente em virtude de sua capacidade técnica e de seu papel de articulador e árbitro. É neste campo de autonomia, limitada, mas com instrumentos próprios de atuação, que podemos entender o lugar institucional da Fecam.

No exercício de suas competências, a Fecam lida com diversas instâncias de governo e organizações públicas. Por ordem de importância, as principais relações que a Fecam estabelece com organismos públicos, segundo seus dirigentes, são: governo do estado de SC, Congresso Nacional, governo federal e Assembleia Legislativa de Santa Catarina (Alesc).

Como exemplo da ação de advocacy da Fecam, sua pauta de atuação tem sido fundamentada em temas, como Programas de Benefícios Tributários; Descentralização Administrativa e Desenvolvimento Regional. Já a pauta federal tem sido pela maior autonomia financeira dos municípios e pela partilha dos recursos decorrentes da exploração do petróleo. Tanto na arena estadual quanto na federal, essas são pautas de reivindicação e de coalizão de interesses, sendo difícil mensurar a consecução de seus objetivos.

Nas relações com os níveis de governo observou-se, na pesquisa de campo, que há sensível dificuldade na relação da Fecam com o governo estadual após a criação das Secretarias de Desenvolvimento Regional (SDRs), em 2003. Ao implantar as 36 SDRs, o governo catarinense não respeitou a demarcação que existia das microrregiões nas quais se situam as 22 associações de municípios e/ou antigos fóruns de desenvolvimento na implantação destas SDRs (conforme analisado mais detidamente por Filippim e Abrucio, 2010). Cada uma dessas secretarias regionais tem um Conselho de Desenvolvimento Regional (CDR) e um quadro administrativo próprio que, por vezes, sombreia e se sobrepõe à estrutura das associações de municípios e, por conseguinte, à Fecam. Trata-se de uma forma de competição entre a ação regionalizada do governo estadual e a dos municípios organizados pela Fecam, modelo que pode ser um obstáculo à coordenação federativa. 
A criação das SDRs em áreas geográficas diferentes daquelas das associações de municípios faz com que os agentes públicos precisem operar nas duas estruturas: na do governo estadual (SDRs) e na municipalista (associações/federação). Como o recurso provindo do estado é negociado e priorizado no Conselho de Desenvolvimento Regional (CDR) das SDRs, essas secretarias acabam trabalhando em paralelo às associações de municípios e, em vez de promoverem a cooperação e a economia de recursos públicos já escassos, geram desperdício de energia administrativa. Isso pode redundar, em alguns casos, no esvaziamento de associações e fóruns, uma vez que os agentes municipais, mesmo com a tradição municipalista catarinense, podem privilegiar o foco onde seja mais provável obter recursos e, neste caso, o Tesouro estadual leva vantagem.

Esta competição com o governo estadual é hoje um dos maiores empecilhos ao desenvolvimento institucional da Fecam, ressaltando um elemento apontado antes pela literatura (Laczynski e Teixeira, 2011): a competição com o poder político estadual é um obstáculo importante à construção da cooperação intermunicipal.

\subsubsection{Processo decisório e inovação}

A grande inovação trazida pela Fecam reside na forma de fazer a orientação técnica aos municípios, uma vez que se especializou em temas que demandam grande competência dos governos locais. Além da profissionalização do seu quadro técnico, a observação dos pesquisadores constatou dois outros elementos: a criação da Escola de Gestão Municipal (Egem) e a busca pela intersetorialidade em suas ações. Somando esses aspectos, a Fecam construiu um arcabouço de inovações com base no desempenho e foco no resultado.

A esse modelo de inovação se juntou a estratégia de atuação com os municípios. Em Santa Catarina, 74\% dos 293 municípios são considerados de pequeno porte e, de maneira isolada, não teriam condições de fazer frente a questões complexas que dependem de grande capacidade técnica e de eficiência em gestão. Assim, a Fecam desenvolveu competências na prestação de serviços e orientação aos municípios. Somou-se a isso sua visão em prol do associativismo territorial, como foi expresso nas entrevistas com seus componentes, o que na verdade é a continuação de uma tradição associativa do estado. Gerou-se, assim, uma equação na qual a criação dos consórcios pela Fecam é, ao mesmo tempo, uma forma de cooperação intermunicipal e uma maneira de avançar na profissionalização em áreas estratégicas da atuação municipal. Neste sentido, a Fecam tem se tornado um órgão que estabelece diretrizes e assessoria técnica, enquanto os consórcios por ela fomentados são executores.

É interessante destacar que, além de ajudar pequenos municípios no processo de consorciamento, a Fecam tem conseguido atrair os municípios médios para arranjos territoriais. Como mostram alguns estudos (Lima, 2000; Spink, 2005, por exemplo), a maioria dos consórcios no Brasil é formada por pequenos municípios, enquanto os médios são bem mais reticentes. Ainda é cedo para se ter uma resposta peremptória sobre a razão de isso ocorrer de forma 
singular em Santa Catarina, mas uma das explicações possíveis é que a Fecam, além de seu papel indutor baseado em recursos técnicos, tem grande reputação, por sua história e por ser um "igual" perante os outros, o que lhe facilitaria atrair mesmo os que normalmente evitam o associativismo e a cooperação territorial.

$\mathrm{Na}$ montagem e no funcionamento da estrutura incumbida de gerir o arranjo, a Fecam, segundo Vedana (2011), ainda precisa melhorar a forma de representação das regiões e incrementar a participação dos municípios na tomada de decisão, principalmente no comprometimento com as ações estratégicas assumidas nas assembleias. Observou-se que faltam indicadores mais claros a partir dos quais os governos locais possam monitorar melhor sua atuação. Cabe ressaltar que outras associações municipalistas pelo Brasil afora geralmente não dispõem também destes instrumentos gerenciais de monitoramento e responsabilização.

\subsubsection{Transparência, publicização e participação social no arranjo}

No que se refere às formas de tornar públicas e transparentes suas ações, observa-se que todas as ações da Fecam são publicadas no site da entidade e são divulgadas por ocasião da Assembleia Geral anual. Contudo, não se observou na análise de nenhum dado da pesquisa, sejam documentos, entrevistas ou na observação de campo, indícios de ações sistemáticas de comunicação com a sociedade civil. É possível que o arranjo tenha aqui uma oportunidade de ampliar e aprofundar sua comunicação tanto com os municípios, seus associados, quanto com o cidadão, foco finalístico da ação municipal e, por conseguinte, da Fecam.

Salienta-se, contudo, que os entrevistados que pertencem à estrutura dirigente da Fecam foram enfáticos ao afirmar que o foco institucional da associação é o município como pessoa jurídica, e não o munícipe. Na verdade, há o temor de haver um choque de legitimidades, pois os prefeitos são os que respondem aos eleitores em seus municípios e ir contra esse parâmetro pode reduzir a credibilidade da Fecam para atuar como assessora e mediadora das relações entre os governos locais.

A única forma de participação mais ampliada dos cidadãos na Fecam acontece nos eventos abertos, como seminários e palestras. Contudo, como ficou evidente na observação empírica durante a coleta de dados, é pouco perceptível a participação nesses eventos de cidadãos que não tenham relação com o quadro funcional e/ou político dos municípios. Vale frisar que a participação de agente público ou político não é o mesmo que participação de cidadão comum. Já os representantes dos municípios participam, sobretudo, das Assembleias Gerais e dos cursos promovidos pela Egem, criada pela Fecam.

Se houvesse uma nova reflexão acerca do foco ou do "cliente" prioritário da Fecam para além do ente jurídico município, atendendo também o cidadão, é possível que fossem abertas oportunidades de participação e diálogo com entidades societais nesse arranjo institucional, conforme observado em outras experiências de associativismo em outras regiões brasileiras, como o caso do Grande ABC e do Projeto Chapada na Bahia (Abrucio e Sano, 2013). 


\subsubsection{Resultados do arranjo}

Em relação aos principais resultados deste arranjo territorial, pode-se citar, como pontos positivos, que a Fecam consegue atender a maioria das reivindicações dos municípios que leva aos outros níveis de governo e tem grande legitimidade junto aos associados. Isto representa incremento ao poder de barganha dos municípios, conferindo legitimidade aos seus interesses nos diálogos com outras instituições de âmbito nacional. O arranjo ganha reconhecimento de sua efetividade, fortalecendo seu caráter de mediador estratégico.

Pode ser citada, como ilustração desta articulação da Fecam, que sua mobilização municipalista foi fundamental para que a Comissão de Assuntos Econômicos (CAE) do Senado aprovasse o projeto que destinou parte dos recursos do Seguro Obrigatório de Danos Pessoais causados por Veículos Automotores de Via Terrestres (DPVAT) aos estados e municípios.

O ponto positivo maior e sua grande inovação é a passagem da atuação mais centrada na advocacy dos municípios para uma ação baseada na ajuda técnica, em especial, na montagem de consórcios. Elegeu-se este exemplo no estudo, pois já há, no Brasil, uma gama variada de associações de advocacy municipalista, mas a maioria delas ainda não atua no apoio técnico às atividades consorciadas e de cooperação. Essa novidade teve como grande efeito aumentar a credibilidade da Fecam como ator federativo.

\subsection{A lógica do associativismo fomentado pela Fecam}

A Fecam tem atividades em diferentes áreas da demanda municipalista, mas o que a diferencia é sua atividade na organização de consórcios intermunicipais. Esse foco de atuação originou-se em sua própria finalidade, expressa no Estatuto da Fecam, no art. 2。: "integrar e promover a cooperação entre os municípios e suas associações, com a criação e participação em entidades da sociedade civil organizada, voltadas ao planejamento, ao desenvolvimento social e econômico local e regional".

Em Santa Catarina, os consórcios intermunicipais constituídos para o enfrentamento de problemas comuns aos municípios têm no Consórcio Intermunicipal da Bacia Hidrográfica do Alto Rio Negro Catarinense, o Consórcio Quiriri, o pioneirismo neste tipo de arranjo, constituído em 1997 (Fuerst, 2011).

A filosofia da cooperação para o enfrentamento de problemas nos quais haja interdependência dos municípios, que norteou a constituição e a natureza da Fecam, tem fundamentado a sua ação no fomento e na articulação de consórcios nos mesmos limites geográficos onde já operam as associações de municípios.

A partir da publicação da Lei dos Consórcios públicos de direito público, em 2005, da qual os dirigentes da Fecam participaram ativamente do debate, a entidade passou a protagonizar a articulação municipalista por meio da estratégia do consorciamento, seguindo sua filosofia de unir forças para solucionar problemas comuns às regiões, racionalizar custos, garantir 
a continuidade da ação pública, minimizar os efeitos da polarização partidária e incentivar a participação dos municípios.

Portanto, a Fecam atua diretamente na criação e na organização de consórcios intermunicipais em diferentes áreas, balizando a atuação e acompanhando a efetividade da ação destes. Essa federação contribui de maneira significativa na cooperação intermunicipal de diferentes formas (Probst, 2011). Diretamente, a Fecam organiza a criação do consórcio, chama para si a responsabilidade de instituí-lo, faz assessoria jurídica e suporte técnico e, em alguns casos, financia o início dos consórcios por meio de custeio para despesas com material de expediente, equipamentos, deslocamentos de profissionais e estrutura física. Indiretamente, a Fecam incentiva a criação de consórcios e fornece assessoria técnica e jurídica após o consórcio entrar em funcionamento.

\subsection{0 fomento da Fecam ao consórcio Ciga}

A Fecam fomentou diretamente a criação do Consórcio de Informática na Gestão Pública Municipal (Ciga) e da Agência Reguladora Intermunicipal de Saneamento (Aris), que é uma agência constituída de forma igualmente consorciada. A Fecam apoia e orienta cerca de 30 consórcios públicos intermunicipais existentes no território catarinense (Brustolin, 2011). Nenhuma outra entidade municipalista brasileira tem essa abrangência na indução e no acompanhamento de consórcios.

Para tomar um caso ilustrativo da ação da Fecam no fomento aos consórcios intermunicipais, elegeu-se, neste estudo, a descrição do papel da Fecam na criação do Ciga, uma vez que esse consórcio tem uma estrutura muito bem definida e está em expansão, o que indica seu sucesso. A partir de estudos técnicos de sua atuação na assessoria especializada na área de informática aos municípios, a Fecam propôs aos municípios a criação de um consórcio e desenhou toda sua estrutura administrativa e de serviços, bem como a forma de operacionalização.

\subsubsection{Tipo do arranjo}

O Consórcio de Informática na Gestão Pública Municipal (Ciga) foi criado, por iniciativa da Fecam, em novembro de 2007. Trata-se de um arranjo de direito público com regime jurídico de direito público. Para motivar os municípios a participar do Ciga, a Fecam realizou reuniões e eventos nos quais divulgou os objetivos e vantagens do consorciamento e convidou os municípios a participar. Segundo Brustolin (2011), foram pelo menos duas reuniões em cada uma das 22 associações de municípios, além da realização de eventos estaduais, chegando a aproximadamente 50 eventos de divulgação e motivação para a participação dos municípios no Ciga.

A área total de abrangência que esse consórcio poderá atingir é a mesma dos municípios associados à Fecam, isto é, de 293 municípios. Todavia, inicialmente o Ciga foi constituído por apenas 13 municípios que celebraram o Protocolo de Intenções. No início de 2013, o Ciga 
já conta com 167 municípios consorciados, o que realça a expansão e o sucesso desse modelo associativo.

O Ciga tem como objetivo desenvolver ferramentas de governança eletrônica, por meio do emprego de tecnologias da informação e comunicação (TIC). Visa ao desenvolvimento, implantação, capacitação, manutenção e suporte de sistemas de tecnologia da informação e comunicação, que permitam o aprimoramento da gestão pública e a inclusão digital.

\subsubsection{Fatores explicam a formação e criação do arranjo}

Entre os fatores explicativos sobre a formação do arranjo, está a necessidade de os municípios adquirirem tecnologias de informação e comunicação (TICs) com menor custo. Os municípios ficavam reféns das empresas que prestam serviços de informática e comunicação oficial. Com o Ciga, além de uma economia de escala, as municipalidades têm maior segurança em perpetuar as ferramentas de informática que precisam e também podem ter maior controle sobre elas, determinando a forma como devem evoluir para atender suas especificidades (Brustolin, 2011).

O consórcio não atua naquilo que já existe na informática dos municípios, mas no desenvolvimento de novas soluções. Como exemplo de seu foco de atuação, o Ciga criou o Diário Oficial dos Municípios de Santa Catarina (DOM/SC) eletrônico. Dessa maneira, antecipou-se às necessidades dos governos locais, criando uma estratégia para a publicação oficial que sempre se constituiu um problema. Com o DOM/SC, além do princípio da transparência, garante-se maior agilidade e a economia de recursos públicos.

Entre os principais atores que agiram no processo de criação do Ciga, vale citar, além da Fecam, o seu centro de tecnologia - que primeiro percebeu a necessidade deste tipo de arranjo - e o Conselho de órgãos fazendários dos municípios de Santa Catarina (Confaz-M/ SC), que entendiam como necessária a estruturação do consórcio. Cabe uma pequena observação aqui: o Confaz-M é mais um exemplo singular da riqueza do associativismo territorial de Santa Catarina.

A aceitação do modelo institucional proposto no Ciga foi relativamente tranquila. $\mathrm{O}$ governo federal, por intermédio da Receita Federal, foi o que teve maiores dificuldades em reconhecer este consorciamento, negando-se, inicialmente, a dar validade jurídica ao DOM/SC. Entretanto, houve diálogo e negociação entre a Fecam e a União e as pendências foram resolvidas. O governo estadual não esteve envolvido na formação do consórcio, mas rapidamente o reconheceu, fator observado especialmente quando o Detran reconheceu a legitimidade do lançamento das multas de trânsito no DOM/SC. Por fim, vale ressaltar o rápido reconhecimento do Ciga pelo Tribunal de Contas de SC.

Quanto à base legal, o arranjo foi formalizado após a promulgação da Lei sobre consórcio público de direito público (no 11.107/2005) e do Decreto Federal no 6.017/2007. O Ciga está alinhado ainda aos seguintes ordenamentos: a) Lei Municipal, pois todos os municípios que se consorciam ao Ciga precisam ratificar essa participação por meio de lei enviada à câmara de 
vereadores; b) Protocolo de Intenções do Ciga promulgado em 29/11/2007; c) Contrato de Consórcio Público, resultado da conversão do Protocolo de Intenções depois de sua ratificação por lei; d) Regimento Interno; e) Resoluções e atos expedidos pela autoridade do consórcio; f) Contrato de programa estabelecido com os municípios consorciados. É importante destacar que os cinco primeiros pontos traduzem a natureza institucional e a estrutura organizacional maior do consórcio, ao passo que os contratos de programa viabilizam a operacionalização e a implementação do consorciamento, conferindo efetividade à gestão associada.

\subsubsection{Fonte de financiamento}

A fonte de financiamento do Ciga é $100 \%$ oriunda dos municípios associados. Quanto aos funcionários, a admissão ao quadro funcional do Ciga acontece mediante concurso público. O Ciga tem, no momento, três funcionários: diretor executivo e dois técnicos em TI. Ressaltase que o princípio da profissionalização é fundamental para as organizações incumbidas de coordenar os arranjos associativos territoriais.

Apesar da equipe reduzida, o Ciga tem alcançado seus objetivos. Entrevistas realizadas no âmbito desta pesquisa mostraram a satisfação dos municípios com o DOM/SC. O fator de maior satisfação citado pelos usuários é o da economia gerada em relação à publicação impressa dos atos oficiais. Contudo, os usuários apontam o distanciamento do cidadão, que ainda não conhece e não se interessa (na visão deles) pela consulta ao DOM. É possível que a aridez do jargão jurídico utilizado num Diário Oficial, ainda que de interesse local, cause estranheza e dificuldades para a população em geral.

Observou-se que na estrutura do Ciga não existe a figura do conselho técnico, o que constitui uma diferença organizacional relevante em comparação com outros consórcios. Usualmente, os conselhos técnicos dos demais consórcios contam com a participação dos secretários municipais. Comumente costuma haver também as câmaras técnicas na estrutura dos consórcios. Ambos, conselho técnico e câmaras técnicas, buscam conferir maior capacidade de articulação e capilaridade dos consórcios junto à gestão pública municipal, além de favorecer a convergência nas políticas públicas dos municípios.

\subsubsection{Grau de autonomia}

Quanto à autonomia do arranjo do ponto de vista institucional, o Ciga tem grau de autonomia médio em relação à Fecam, pois ela lhe fornece a estrutura física e a legitimidade de que necessita para alcançar seus objetivos. Em relação aos municípios consorciados, a dependência financeira é elevada, uma vez que o Ciga depende do que arrecada dos seus membros. Em 2011, a arrecadação mensal do Ciga foi de R $\$ 28$ mil; os menores municípios colaboram com $\mathrm{R} \$ 224,00$ e os maiores com R\$2.464,00 ao mês. Já de janeiro a maio de 2013, a arrecadação 
do Ciga foi de R\$298.478,00 (média de R\$ 74.619,50/mês). Obviamente que não é desejada a autonomia do consórcio em relação aos municípios associados, já que ele representa os interesses deles. O desejado é a velocidade de resposta às demandas. Autonomia deve ser conquistada em relação a interesses externos, como interferência partidária e de agentes não previstos em seu estatuto.

\subsubsection{Processo decisório e a inovação}

O processo decisório deste arranjo territorial acontece por meio de uma fase prévia de legitimação na qual as políticas do consórcio são consensuadas entre seus associados. Assim que previamente consensuadas, as decisões de escopo mais abrangente e estratégico são tomadas de forma efetiva na Assembleia Geral. Já as decisões de caráter mais rotineiro e de manutenção são tomadas diretamente pelo diretor executivo.

Constatou-se na pesquisa que as ações e os documentos do Ciga são publicados em seu site e assembleias. Uma forma de verificar a efetividade da transparência dos atos oficiais municipais proporcionada pelo Ciga se dá por meio do controle de acessos das publicações no Diário Oficial dos Municípios de Santa Catarina (DOM/SC). Técnica do Ciga informou aos pesquisadores que monitora as vistas ao DOM/SC e que, no ano de 2012, houve 236.140 acessos, enquanto de janeiro a junho de 2013 houve 184.000 acessos ao DOM/SC.

\subsubsection{Instrumentos de avaliação}

Embora não haja instrumento específico e sistemático de avaliação de resultados, o Ciga serve-se da comparação entre o que foi planejado (Plano de trabalho anual do Ciga) e o que foi implementado (Relatório anual) para analisar seus resultados. Um dos indicadores utilizados é a economia estimada com a publicação dos atos no DOM/SC. Conforme análise do exercício de 2012, a economia de todos os municípios que utilizam o DOM/SC (principal Programa do Ciga) foi de $\mathrm{R} \$ 21.223 .240,00$, quando somamos a economia estimada de cada município que publicou no DOM/SC.

\subsubsection{Participação social no arranjo}

Observa-se que a participação do cidadão não ocorre de maneira direta, pois quem participa do Ciga são os municípios. O Ciga recebe, no entanto, sugestões e solicitações vindas do público em geral por telefone e por meio do site. Essas sugestões são incipientes em número e constituem um fraco mecanismo de interlocução com o cidadão. 


\subsubsection{Fatores explicam a permanência e sobrevivência do arranjo}

Segundo um dos entrevistados (Brustolin, 2011), são pontos positivos da atuação do Ciga a disseminação de conhecimento e experiências existentes e/ou novas para os municípios, a implementação de políticas de informação e comunicação mais completas e padronizadas, a criação de procedimentos para publicação oficial. Quanto aos pontos negativos, destaca o entrevistado que ainda existe uma limitação de recursos financeiros e precisariam ter uma equipe maior. Aponta, ademais, uma grande dificuldade para o consorciamento nestes moldes no Brasil: o engessamento político-burocrático presente na Lei de Consórcios Públicos, como o observado na necessidade, expressa na lei, de que algumas decisões do consórcio sejam ratificadas por todos os municípios.

Essa regra faz com que, em cada mudança e/ou avanço necessários ao Ciga, tenha de haver uma tramitação específica em todas as câmaras municipais para ratificação de tal alteração. Cabe comentar que esta dificuldade de governança não pode gerar um argumento que reduza o peso dos municípios nas decisões consorciadas. Mas é preciso ter maior flexibilidade para que os governos locais não acreditem que o custo de consorciamento seja maior do que atuar solitariamente no campo das políticas públicas.

Os dirigentes do consórcio não percebem maiores dificuldades na execução das atribuições do Ciga, e explicam a permanência e sobrevivência do arranjo por três fatores: a) programas objetivos que atendem questões pontuais dos municípios; b) bom canal para resolver problemas comuns dos municípios; e c) estreita relação com a Fecam. É interessante notar que, na visão dos seus dirigentes, há pouca preocupação de que o Ciga se enfraqueça. Ou seja, acreditam que, ao atender bem à demanda por economicidade, os gestores públicos municipais tenderão a manter o arranjo.

De qualquer modo, é essencial ressaltar que sem o aval e o apoio técnico da Fecam, o Ciga provavelmente não teria existido e teria muitas dificuldades de se manter e de se expandir. Aliás, a expansão do modelo foi bastante significativa: ele começou em 2007 com 13 municípios associados, em 2011 chegou a 81 membros, em 2013 já são 167 municípios consorciados.

O sucesso do Ciga, como de resto da própria atuação de apoio ao consorciamento da Fecam, também se expressa em atrair os pequenos e médios municípios da mesma maneira, enquanto na maioria das outras experiências parece que os consórcios públicos intermunicipais se concentram fundamentalmente nas municipalidades menores (Freitas Júnior e Mesquita, 2010). Isso pode ser resultado da atuação integradora e legitimadora da Fecam, que representa o conjunto dos municípios catarinenses, levando assim à atração de municipalidades médias que geralmente preferem não dividir poder com os pequenos.

Sobre a possibilidade de interesses conflitantes com outras fontes de serviços similares, como o Diário Oficial do Estado (DOE), não se percebeu a existência de conflito, pois muitos municípios ainda utilizam o DOE para suas publicações, mesmo aqueles que têm o DOM/SC como órgão oficial. Além disso, não se permite a publicação de terceiros (que não municípios) no DOM/SC, os quais continuam a usar o DOE. 
Em relação aos aspectos político-partidários e às disputas deles originadas, parecem não afetar de maneira significativa os arranjos, seja a Fecam ou os consórcios (Probst, 2011). É possível que a atuação bem focada e pragmática do Ciga não represente ameaça ao status quo. Contudo, quando os consórcios atingirem áreas que constituem arenas de disputas partidárias, esse componente pode fazer emergir conflitos de interesse. Observa-se que estas situações conflitantes ocorrem mais frequentemente nas regiões metropolitanas e/ou de forte densidade urbana, com maior ou menor conurbação, o que não é o caso da grande maioria dos municípios catarinenses.

\section{Conclusão}

A Fecam atua na criação e na manutenção de consórcios intermunicipais por meio da articulação de temas de interesse, partindo de demandas por soluções conjuntas que atendam às problemáticas dos municípios. A adesão do município aos consórcios propostos pela Fecam é livre e se dá conforme o consórcio vai apresentando resultados, especialmente aqueles voltados para a eficiência e a economicidade.

Na experiência estudada, observou-se que o argumento da racionalização de recursos é o principal motivador para que o município adote a solução da cooperação intermunicipal. Percebe-se, portanto, uma elevada dose de pragmatismo que orienta a ação dos gestores públicos municipais em Santa Catarina. A saída pela formação de um consórcio fundada nas vantagens econômicas, no caso da Fecam, não é contraditória com a filosofia do associativismo, uma vez que essa instituição é que gerou o colchão de legitimidade e credibilidade que dá base à cooperação. Contudo, é necessário refletir se esse aspecto que estimulou a construção da cooperação intermunicipal será suficiente para garantir a sustentabilidade desses consórcios públicos municipais ao longo do tempo.

Se, por um lado, a soma do histórico associativista catarinense com o modelo de instituição municipalista mediadora fundada em forte profissionalização, ajudando assim municípios mais frágeis do ponto de vista administrativo, é aspecto que favorece a estabilidade do modelo, por outro, o conflito com o governo estadual, por conta das SDRs, pode levar a um choque de legitimidades com os prefeitos. Esse é um dilema a ser enfrentado no caso da Fecam, o que traz uma lição importante para outras experiências de cooperação intermunicipal: é preciso garantir que a ação cooperativa horizontalizada não tenha choques com as dimensões verticais do federalismo, em particular na relação com o poder político estadual.

Entre os aspectos mais positivos da experiência e que pode ser disseminado para outros casos similares, destaca-se que o fundamento da ação da Fecam no consorciamento intermunicipal vem da sua ação de advocacy legitimada junto aos municípios. Primeiro, porque ela não é vista como algo ameaçador que represente a perda do controle sobre políticas públicas que possam inviabilizar sua reeleição ou sua capacidade de atrair apoio. Além disso, o fato de que todas as ações da Fecam são negociadas com os seus sócios (os municípios) e amplamente analisadas nos seus Conselhos faz com que ela dê passos legitimados. 
Outro aspecto relevante nessa experiência é a grande dose de conhecimento técnico e capacidade de gestão presente na equipe da Fecam e do consórcio observado, o Ciga. A especialização na prestação de serviços aos municípios permite que a Fecam gere, acumule e dissemine soluções para as demandas dos municípios. Esse aspecto favorece a perspectiva da continuidade da experiência do consorciamento.

Aqui há um ponto fundamental para a discussão da cooperação intermunicipal no Brasil: não basta conhecer quais são os fatores que facilitam a formação de consorciamentos, sendo fundamental também a reflexão sobre o que leva à manutenção desses arranjos. A literatura referente ao assunto praticamente silencia sobre esse ponto. O exemplo da Fecam revela que sua atuação como entidade mediadora vista como neutra pelos governos locais os quais na verdade participam diretamente dela - e sua capacidade de fornecer respostas e instrumentos técnicos capazes de solucionar problemas básicos das municipalidades são dois elementos que dão maior sustentabilidade a essa estratégia de cooperação por meio de consórcios. Outras associações municipalistas poderiam repetir esse padrão, caso consigam construir sua legitimidade perante os prefeitos e se montarem uma estrutura profissional de apoio aos governos locais, tendo como intenção declarada a construção de modelos de associativismo territorial.

O caso da Fecam revela uma dupla legitimação que favorece a construção de formas de associativismo territorial. De um lado, os municípios só aceitam ceder parte de sua autonomia, por meio do consórcio, porque confiam muito na Fecam, seja pela sua história de lutas municipalistas, seja (sobretudo) por sua capacidade técnica. Por outro lado, a Fecam é fortalecida neste processo de produção de consorciamentos, aumentando sua legitimidade para atuação no campo da advocacy e abrindo, quem sabe, uma nova fronteira que poderá gerar recursos para financiamento da associação. Está aí uma lição que poderia ser disseminada por outros grupos municipalistas, que poderiam reforçar assim sua legitimidade: a atuação como advocacy é fortalecida se a entidade municipalista assume, como orientação estratégica, o papel de articuladora de políticas.

A construção e a manutenção do consorciamento dependem da capacidade de combinar inovação institucional com inovação no conteúdo da política. A ilustração de forma de atuação da Fecam apresentada neste estudo, o Ciga, revela um duplo caráter inovador: na forma como se desenvolveu o consórcio, pela via de uma associação de municípios e pelo conteúdo do consorciamento, que é a produção de um Diário Oficial eletrônico para os municípios, cortando custos e, ao mesmo tempo, aumentando a transparência governamental.

O que se pode depreender deste caso é que muito do sucesso dos arranjos associativos territoriais está na capacidade de conciliar inovações na forma - rompendo com o modelo muito homogeneizador e compartimentalizado do federalismo brasileiro - e no conteúdo, uma vez que a permanência e a aceitação de tais institucionalidades de consorciamento vinculam-se bastante à obtenção de resultados concretos para um problema de política pública, o que exige muitas vezes um ângulo diferente do padrão até então prevalecente.

Quanto aos aspectos mais problemáticos da experiência estudada, aponta-se, primeiramente, a necessidade de fortalecer a participação efetiva da sociedade civil, seja na Fecam, 
seja nos consórcios por ela fomentados. A criação de canais para efetivar a participação e o controle social, indicadores-chave para a análise de arranjos associativos, poderá fornecer transparência e possibilidade de responsabilização maior para as atividades da Fecam e dos consórcios intermunicipais, além de propiciar a interface com os cidadãos residentes neste território, cujo atendimento de suas demandas é o foco da ação dos governos. Sugere-se, por exemplo, a criação na estrutura decisória dos consórcios de um mecanismo para a participação dos conselhos de políticas públicas que existem em todos os municípios, conforme sua área de atuação, coerente com a dos consórcios.

Outro aspecto que apresenta uma oportunidade de melhoria que pode nortear esta e outras experiências de consorciamento é a implantação de cultura de mensuração dos resultados, por meio da adoção de indicadores de desempenho e de controle sistemático da performance desses indicadores, dando ciência dos mesmos tanto aos municípios associados quanto à sociedade civil.

Cabe ressaltar que, no aspecto das relações com o poder público de outras esferas, tanto o governo estadual quanto o federal não têm atuado fortemente nesta experiência — no caso estadual chega até a haver uma competição. Para construir um bom ambiente de consorciamento, é preciso que haja relações menos competitivas entre o governo estadual e as entidades municipalistas. Evidentemente que conflitos são corriqueiros numa federação, mas é preciso ter canais de diálogo e respeito mútuo - o pluralismo federativo, tal qual definido por Burgess (1993). O que está em jogo, do ponto de vista do futuro do associativismo territorial brasileiro, é que o governo estadual muitas vezes compete pelo controle dos municípios, quebrando a lógica da autonomia, que permite semear um espaço para os arranjos intergovernamentais dentro do federalismo democrático.

Para fortalecer a lógica de consorciamento intermunicipal, seria interessante se os demais níveis de governo se somassem à Fecam no processo de articulação dos municípios para objetivos regionais comuns. $\mathrm{O}$ fato é que, quanto mais apoio vertical houver às formas de consorciamento, mais chances haverá de se construir uma sólida articulação entre os municípios.

O caso da Fecam revela, enfim, que é possível favorecer a cooperação se a articulação intergovernamental for colocada na frente do interesse de cada município, sem que as municipalidades deixem de se representar nesse processo, e caso o modelo se baseie numa proposta profissional e inovadora de gestão. A sustentabilidade desse modelo não atrapalha a motivação política dos prefeitos, pois, ao contrário, ao proporcionar soluções eficientes compartilhadas regionalmente, permite um jogo de cooperação que reduz as incertezas presentes na disputa política local. Como se vê, trata-se de uma resposta que considera tanto o realismo como o dever ser.

\section{Referências}

ABRUCIO, Fernando L. A coordenação federativa no Brasil: a experiência do período FHC e os desafios do governo Lula. Revista de Sociologia Política, n. 24, p. 41-67, jun. 2005. 
ABRUCIO, Fernando L. Os barões da federação: os governadores e a redemocratização brasileira. São Paulo: Hucitec; USP, 1998.

ABRUCIO, Fernando L.; SANO, Hironobu. Associativismo Intergovernamental: experiências brasileiras. Brasília: Fundação Instituto para o Fortalecimento das Capacidades Institucionais - IFCI; Agência Espanhola de Cooperação Internacional para o Desenvolvimento - AECID; Ministério do Planejamento, Orçamento e Gestão — MPOG; Editora IABS, 2013.

ABRUCIO, Fernando L.; SANO, Hironobu; SYDOW, Cristina T. Radiografia do associativismo territorial brasileiro: tendências, desafios e impactos sobre as regiões metropolitanas. In: KLINK, Jeroen (Org.). Governança das metrópoles. São Paulo: Annablume, 2011.

ABRUCIO, Fernando L.; SOARES, Márcia M. Redes federativas no Brasil: cooperação intermunicipal no Grande ABC. São Paulo: Cedec; Fundação Konrad Adenauer; Oficina Municipal, 2001. v. 24.

AGRANOFF, Robert. Managing within the matrix: do collaborative intergovernmental relations exist? Publius: the Journal of Federalism, v. 31, n. 2, p. 31-56, Spring 2001.

BOURDIEU, Pierre. Le capital social: notes provisoires. Actes de la Recherche en Sciences Sociales, v. 31, p. 2-3, 1980.

BRELÁZ, Gabriela de. Advocacy das organizações da sociedade civil: principais descobertas de um estudo comparativo entre Brasil e Estados Unidos. In: ENCONTRO NACIONAL DE PÓS-GRADUAÇÃO EM ADMINISTRAÇÃO, 31, 2007, Rio de Janeiro. Anais do ENANPAD. Rio de Janeiro: ENANPAD, 2007. v. 31, p. 1-16.

BRUSTOLIN, Edinando. Entrevista: Consórcio de Informática na Gestão Pública Municipal (Ciga). Diretor executivo do Ciga. Entrevistadora: Eliane Salete Filippim. Florianópolis: 13h30min., 21 mar. 2011.

BURGESS, Michael. Federalism and federation: a reappraisal. In: BURGESS, Michael; GAGNON, Alain (Org.). Comparative federalism and federation. Londres: Harvester/Wheatsheaf, 1993.

CASTELLANO, Maria. Relações entre o poder público e a sociedade na gestão dos recursos hídricos: o caso do Consórcio Intermunicipal das Bacias Hidrográficas dos Rios Piracicaba, Capivari e Jundiaí. Tese (doutorado em ciências ambientais) — Universidade de São Paulo, São Paulo, 2007.

CIGA. Consórcio de Informática na Gestão Pública Municipal. Florianópolis, 2011. Disponível em: <www.ciga.sc.gov.br/>. Acesso em: 7 maio 2011.

COUTINHO, Frederico M. A. Os consórcios públicos como instrumento potencializador de políticas públicas. In: ENCONTRO NACIONAL DE PÓS GRADUAÇÃO EM ADMINISTRAÇÃO, 34., 2010, Rio de Janeiro. Anais... Rio de Janeiro: ANPAD, 2010. p. 1-16.

DANIEL, Celso. Autonomia municipal e as relações entre os estados e a União. In: HOFMEISTER, W.; CARNEIRO, J. M. B. (Org.). Federalismo na Alemanha e no Brasil. São Paulo: Fundação Konrad Adenauer, 2001.

DIEGUEZ, Rodrigo C. Consórcios intermunicipais em foco: debate conceitual e construção de quadro metodológico para análise política e institucional. Cadernos do Desenvolvimento, v. 6. n. 9, p. 291-317, 2011. 
DIETZ, Thomas; OSTROM, Elinor; STERN, Paul C. The struggle to govern the commons. Science, v. 302, n. Special Section - Tragedy of the commons?, p. 1907-1912, dez. 2003. Disponível em: <www.sciencemag.org>. Acesso em: 5 out. 2010.

ELAZAR, Daniel J. Exploring federalism. Alabama: The University of Alabama Press, 1987.

FECAM. Federação Catarinense de Municípios. Florianópolis. 2011. Disponível em: <www.fecam. org.br/>. Acesso em: 7 mar. 2011 e jun. 2013.

FILIPPIM, Eliane S.; ABRUCIO, Fernando L. Quando descentralizar é concentrar poder: o papel do governo estadual na experiência catarinense. RAC — Revista de Administração Contemporânea, v. 14, n. 2, p. 212-228, 2010.

FRANZESE, Cibele. Federalismo cooperativo no Brasil: da Constituição de 1988 aos sistemas de políticas públicas. Tese (doutorado em administração pública e governo) — Escola de Administração de Empresas de São Paulo, FGV, São Paulo, 2010.

FREITAS JÚNIOR, Dionysio B.; MESQUITA, Daniel L. Consórcios Intermunicipais de Políticas Públicas em Minas Gerais: redes para a prestação eficiente de serviços ao cidadão. In: ENCONTRO NACIONAL DE PÓS-GRADUAÇÃO EM ADMINISTRAÇÃO, 34., 2010, Rio de Janeiro. Anais... Rio de Janeiro: ANPAD, 2010. p. 1-14.

FUERST, Leoni. O consórcio Quiriri [mar. 2011]. Secretária Municipal de Planejamento e Meio Ambiente. [mensagem de trabalho]. Mensagem recebida por: <eliane.filippim@unoesc.edu.br>, em 28 mar. 2011.

GODOY, Arilda S. Estudo de caso qualitativo. In: GODOI, Christiane K.; BANDEIRA-DE-MELLO, Rodrigo; SILVA, Anielson B. (Org.). Pesquisa qualitativa em estudos organizacionais: paradigmas, estratégias e métodos. 2. ed. São Paulo: Saraiva, 2010. p. 115-143.

LACZYNSKI, Patricia; TEIXEIRA, Marco A. C. Os limites de um consórcio intermunicipal em condições assimétricas de poder: o caso do Cinpra no Maranhão. Cadernos Adenauer, Rio de Janeiro, v. 12, n. 4, p. 141-160, 2011.

LÍCIO, Elaine C. Sucessos e limites da recentralização: o Bolsa Família no modelo federativo brasileiro. Projeto de qualificação de tese (doutorado) — Instituto de Ciências Humanas, Universidade de Brasília, Brasília, 2010.

LIMA, Ana P. G. Os Consórcios Intermunicipais de Saúde e o Sistema Único de Saúde. Cadernos de Saúde Pública, Rio de Janeiro, v. 16, n. 4, p. 985-996, out./dez. 2000.

MACHADO, Gustavo G. Gestão metropolitana e autonomia municipal: dilemas das transações federativas. Belo Horizonte: Ed. PUC Minas, 2009.

NEVES, Luiz A.; RIBEIRO, José M. Consórcios de saúde: estudo de caso exitoso. Cadernos de Saúde Pública, Rio de Janeiro, v. 22, n. 10, p. 2207-2217, out. 2006. Disponível em: <www.scielo.br/scielo. php?script=sci_arttext\&pid $=$ S0102 $>$. Acesso em: 10 mar. 2011.

OSTROM, Elinor. Governing the commons. Nova York: Cambridge University Press, 1990. 
PRADO, Otávio P. et al. Inovações e consórcios intermunicipais: a experiência do Consórcio Quiriri. In: ENCONTRO NACIONAL DE PÓS-GRADUAÇÃO EM ADMINISTRAÇÃO, 34., 2010, Rio de Janeiro. Anais... Rio de Janeiro: ANPAD, 2010. p. 1-17.

PROBST, Marcos. Entrevista: o papel da Fecam no fomento aos consórcios [mar. 2011]. Diretor executivo Aris. Entrevistadora: Eliane Salete Filippim. Florianópolis: 21 mar. 2011.

SPINK, Peter. The intermunicipal consortia in Brazil: an institutional introductions. In: CONGRESSO INTERNACIONAL CLAD, X, 2005, Santiago, Chile. Anais do X Congresso Internacional del Clad sobre la reforma del Estado y de la Administración Publica. Santiago: Clad, 2005. v. 1, p. 1-13.

SPINK, Peter.; TEIXEIRA, Marco A. C.; CLEMENTE, Roberta. Governança, governo ou gestão: o caminho das ações metropolitanas. Cadernos Metrópole, v. 11, n. 22, p. 453-476, jul./dez. 2009.

VEDANA, Celso. O papel da Fecam no fomento aos consórcios [mar. 2011]. Diretor executivo da FECAM. Entrevistadora: Eliane Salete Filippim. Florianópolis: 21 mar. 2011.

YIN, Robert K. Estudo de caso: planejamento e métodos. Porto Alegre: Bookman, 2005.

Fernando Luiz Abrucio é doutor em ciência política pela Universidade de São Paulo (USP) e é pesquisador do Programa de Mestrado e Doutorado em Administração Pública e Governo da EAESP/FGV. E-mail: fabrucio@gmail.com.

Eliane Salete Filippim fez pós-doutorado em administração pública e governo pela Escola de Administração de Empresas de São Paulo (EAESP/FGV), é doutora em engenharia de produção e sistemas pela Universidade Federal de Santa Catarina (UFSC), atua no mestrado profissional em administração pela Universidade do Oeste de Santa Catarina (Unoesc). E-mail: eliane.filippim@unoesc.edu.br.

Rodrigo Chaloub Dieguez é mestre em ciências sociais pela Pontifícia Universidade Católica do Rio de Janeiro (PUC-Rio); Valec Engenharia, Construções e Ferrovias S.A., empresa pública vinculada ao Ministério dos Transportes. E-mail: rodrigoodieguez@hotmail.com. 